\title{
AC̣ÕES REFLEXIVAS NA PRÁTICA DE ENSINO DE QUÍMICA
}

\author{
Agilson Nascimento Souza* \\ Suely Alves da Silva** \\ Rosane Maria Alencar Silva***
}

RESUMO: O objeto de investigação deste trabalho diz respeito aos aspectos relativos a práticas reflexivas e ao discurso junto a dois professores de Química da rede estadual de ensino de Pernambuco que desenvolvem suas atividades docentes há vários anos, sendo, por isso, considerados experientes. Foram gravados e analisados, qualitativamente, vídeos de aulas e entrevistas realizadas com esses docentes tendo como base teorias prático-reflexivas. As análises dos dados evidenciam que os docentes se apropriaram de aspectos característicos da prática reflexiva no âmbito discursivo, entretanto, em situações de aulas, suas ações se constituíram caracteristicamente tradicionais.

Palavras-chave: Formação Continuada. Ensino de Química. Prática Reflexiva.

\section{REFLEXIVE ACTIONS IN THE PRACTICE OF CHEMISTRY TEACHING}

ABSTRACT: This work consists of an investigation about aspects related to the reflexive practices and the speech, between two chemistry teachers from the statewide network of Teaching of the State of Pernambuco who develop their teaching activities for several years, being therefore, considered experienced. In addition to that, qualitatively analyzed interviews and videos of lessons from these teachers were recorded, and used as theories of practical-reflective input. The analyses of the data showed up that teachers appropriated themselves of aspects that were characteristic of the reflexive practice in the discursive context, meantime, in situations of classrooms, the actions of those teachers appeared characteristically traditional.

Keywords: Permanent Formation. Chemistry Teaching. Reflexive practice.
* Mestre em Ensino das Ciências pela Universidade Federal Rural de Pernambuco (UFRPE). Atualmente é Químico da Universidade Federal de Pernambuco (UFPE). Professor de Química do Ensino Básico da Rede Estadual de Pernambuco. agilson_ns@yahoo.com.br

* Doutora em Ciências - Área de Concentração: Físico-

Química. Professora Associada nível 01 da Universidade Federal Rural de Pernambuco, com experiência na área de Educação, ênfase em Ensino Aprendizagem e Formação Continuada de Professores. suelyalves@yahoo.com

*** Doutora em Sociologia. Professora do Departamento de Sociologia da Universidade Federal de Pernambuco (UFPE). Email:.rosanealencar@gmail.com 


\section{INTRODUĈ̣̃O}

O presente estudo objetivou compreender, a partir de ações e concepções de dois professores de Química da rede oficial de ensino do estado de Pernambuco, como estes professores se apresentavam, na dimensão profissional, no que diz respeito à perspectiva reflexiva na prática de ensino. Para isso, buscamos analisar a prática de ensino dos dois professores com foco nas ações prático-reflexivas, e ainda analisar depoimentos de ambos acerca de concepções reflexivas na prática de ensino.

Caracterizamos a prática reflexiva segundo perspectivas epistemológicas de J. Dewey; de D. Schön, e de K. Zeichner(1993). A concepção de Zeichner, dada sua abrangência, constituiu-se como principal referencial para observação e análise das ações reflexivas dos professores cujas práticas estiveram sob investigação.

Para apreciação dos dados, utilizamos a proposta de análise de conteúdo na perspectiva de Bardin (1997), que foi aplicada aos dados das entrevistas e às trajetórias discursivas de aulas videografadas e convencionadas conforme padrão interacional por Marcuschi (2005).

No tocante à formação, Zeichner (1993) entende que "cada um deve responsabilizar-se por seu próprio desenvolvimento profissional (...) a universidade pode, quando muito, preparar o professor para começar a ensinar" (p. 17). O referido autor questiona os cursos de formação de professores baseados na racionalidade técnica e adverte para a necessidade de envolvê-los nos processos de construção dos programas para a formação docente.

Não apenas concordamos com Zeichner como, ainda, ressaltamos a importância da formação do professor no desenvolvimento de sua prática docente, em local de trabalho. Ao mesmo tempo, observamos que isso não tem ocorrido.

Motivados por antigos questionamentos relativos à formação alicerçada na racionalidade técnica, pela aproximação com teorias de práticas docentes reflexivas, e pela consideração da possibilidade de contribuir para a melhoria do ensino de Química por meio da pesquisa, investimos na construção do presente trabalho.

Maldaner (2000) relata que a partir dos anos 1980 foi constatado que professores de Ciências, graduados na instituição em que ele ministrava aulas, limitavam-se a tentar transmitir conteúdos de livros didáticos em suas práticas de ensino nas escolas. Além disso, suas aulas eram semelhantes às que haviam tido na universidade, centradas na sistematização de conteúdos característicos de uma ciência constituída. Pereira (2000) atenta para a necessidade de o professor negar a ideia de transmissor de conhecimentos e superar modelos de licenciaturas baseados na sobreposição do processo de ensino pelos conteúdos.

Para tanto, levantamos os seguintes questionamentos: estarão os professores de Química apresentando ações reflexivas no cotidiano de suas práticas docentes? Como tais professores concebem, no âmbito discursivo, a formação e atuação prático-reflexiva? Tais questionamentos nortearam e fomentaram a presente pesquisa. 


\section{PANORAMA DAS INVESTIDAS DO ENSINO DE QUÍMICA NA PERSPECTIVA REFLEXIVA NO BRASIL}

Devido à tradição e à incidência de trabalhos voltados para o ensino de ciências da natureza, área de atuação dos professores pesquisados, definimos os Encontros Nacionais de Pesquisas em Educação em Ciências (ENPEC) como principal fórum de consulta. Escolhemos o primeiro decênio dos ENPEC por causa da proximidade do surgimento dos debates acerca do professor reflexivo no Brasil e por ser um período supostamente significativo para estudo, conforme descrito a seguir.

Zanon e Schnetzler (2003) realizaram a pesquisa Interações triádicas entre licenciandos, professores e formadores na licenciatura de química/ ciências, que teve como objetivo investigar se tais interações poderiam contribuir para a superação da formação ambientalista.

Almeida e Bastos (2003) realizaram a pesquisa O professor de quimica e o processo reflexivo sobre sua ação em sala de aula, que aponta a reflexão como base fundamental para a docência e alerta que o modelo de aprendizagem por mudança conceitual mantém a mesma lógica do ensino tradicional por centrar-se exclusivamente na racionalidade técnica.

Silva, Sales e Chinen (2005) realizaram a pesquisa Investigando a prática docente dos professores de química D.E. - Mauá, com a qual discutiram e confrontaram ideias com pressupostos dos PCNs. Os autores tiveram como objetivo resgatar e potencializar, no professor, uma visão positiva a respeito do ensino de Química, além de orientá-lo no sentido de se tornar um profissional reflexivo.

Mortimer e Silva (2003) realizaram a pesquisa Formação continuada e mudanças nas práticas pedagógicas: o que dizem os professores de química, um estudo de evidências de mudanças na prática pedagógica de professores participantes de um programa de formação. Segundo os autores, o modelo utilizado pelo programa fundamentava-se no chamado modelo de racionalidade prática, o que exigia dos professores formandos uma atuação crítica e reflexiva em sala de aula.

Santos e Santos (2005) realizaram a pesquisa Formação continuada de professores de química: qual modelo, qual formação? Nela, fazem um relato de uma experiência em formação continuada com professores do Ensino Médio de escolas públicas, uma introdução da reflexão sobre a prática pedagógica dos professores mediada por professor da Universidade.

Nery e Maldaner (2009) realizaram a pesquisa Ações Interativo-Reflexivas na Formação Continuada de Professores, relatando uma investigação no projeto Folhas como proposta de formação continuada de professores. O projeto faz parte de um programa da Secretaria de Estado da Educação do Paraná que é realizado de 2004 até data atual.

Altarugio e Villani (2010) realizaram a pesquisa O papel do formador no processo reflexivo de professores de ciências, cujo objetivo foi discutir as práticas e os discursos de uma docente que é formadora de professores de Ciências e possui um nível de experiência bastante elevado na formação inicial e continuada. 
Rosa-Silva, Júnior e Laburú (2010) realizaram a pesquisa Análise das reflexões da professora de ciências sobre a sua relação com os alunos e implicações para a prática educativa. O trabalho aborda reflexões de dimensões discentes de uma docente que tem sua prática no ensino de Ciências.

Paula (2011) realizou a pesquisa O Professor como agente da construção da teoria $e$ da prática, enfatizando uma discussão sobre alguns conceitos atrelados à prática de ensino, sobretudo ao professor que está envolvido nessa prática, buscando, também, evidenciar a relevância de se rever a função que o professor desenvolve atualmente na conjuntura social.

Acreditamos que novas contribuições para o ensino da Química poderão ser dadas por meio da investigação da prática dos professores colaboradores em condições relativamente naturais. Para isso, esta pesquisa foi embasada nas concepções de Zeichner, cujo enfoque remete à docência, dentre outros aspectos, e a questões políticas e sociais, conforme constataremos mais adiante.

\section{PROFESSOR REFLEXIVO: ALGUMAS CONCEPC̣ÕES}

Zeichner (1993) resgata de Dewey a definição de ação reflexiva como “algo que implica uma consideração ativa, persistente e cuidadosa daquilo que se pratica, à luz dos motivos que a justificam e das consequências a que conduz" (p. 18).

Segundo autor, Dewey baseou a ação reflexiva em três atitudes: abertura de espírito: atender a possíveis opiniões e admitir a possibilidade do erro; responsabilidade: ponderação cuidadosa das consequências de uma determinada ação; e sinceridade.

Donald Schön propôs um modelo para a formação de profissionais reflexivos como alternativa à formação baseada na racionalidade técnica. Schön (2000) defende o "ensino prático reflexivo" - a reflexão-na-ação - como modo de atingir um ensino de competências profissionais que pode ajudar a resolver problemas reais do cotidiano. Em seus argumentos sobre o ensino prático reflexivo, ele distingue "reflexão-na-ação" de "conhecer-na-ação". Segundo o autor, conhecer-na-ação compreende as performances físicas, observáveis, como andar de bicicleta, porém, impossíveis de ser verbalmente explicitadas; já a reflexão-na-ação diz respeito aos questionamentos de estruturas e pressupostos do ato de conhecer-na-ação com vistas à reestruturação de estratégias de ação e compreensão de fenômenos.

A reflexão-na-ação, sugerida por Schön em alternativa ao conhecer-na-ação, em certa medida favorece a inserção mais consciente dos sujeitos na sociedade.

Schön (2000) formula sua perspectiva da ação reflexiva de acordo com três aspectos:

I. A reflexão na prática: em sentido metafórico, é uma conversação reflexiva com os materiais de uma situação (p. 35).

II. A reflexão da prática: a surpresa levando à reflexão dentro do presente-da-ação.

III. A reflexão na prática e sobre a prática: uma descrição do saber tácito implícito na ação. 
Schön (2000) ainda acrescenta que "podemos refletir sobre a ação, pensando retrospectivamente sobre o que fizemos, de modo a descobrir como nosso ato de conhecer-na-ação pode ter contribuído para um resultado inesperado" (p. 22).

Rodrigo e Sobrinho (2007) entendem que a reflexão-na-ação reporta-se ao pensamento do professor no ato do ensino, permitindo-lhe improvisar, resolver problemas, decidir diante do inusitado; enquanto na reflexão-sobre-a-ação o professor elabora teorias sobre sua prática.

\section{A FORMAC̣ÃO PROFISSIONAL NA PERSPECTIVA DA RACIONALIDADE TÉCNICA}

Tradicionalmente, em instituições de Ensino Superior a formação de profissionais tem se dado segundo padrão da racionalidade técnica em que o conteúdo é recebido de modo acumulativo e progressivo, quase sempre se constituindo em arsenal destinado à solução de problemas no campo de ação profissional (SCHÖN, 2000).

Zeichner (1993) orienta para que o enfoque da prática reflexiva seja usado na análise da formação de professores, e que essa prática esteja atrelada ao contexto estrutural político. Ademais, adverte quanto à necessidade de os professores participarem ativamente de processos de formação, o que comumente não acontece. Além disso, destaca que a reflexão também significa reconhecer que os professores são corresponsáveis na construção de conhecimentos relativos ao ensino de qualidade, não sendo tal construção restrita às universidades e centros de investigação. Para Zeichner (1993), professor reflexivo é aquele que considera a riqueza da experiência que reside na prática dos bons professores. O processo de compreensão e melhoria do ensino deve começar pela reflexão sobre a própria experiência, e o tipo de saber inteiramente tirado da experiência dos outros é, no melhor dos casos, pobre e, no pior, uma ilusão. Para o referido autor, professores, nessa perspectiva, devem reconhecer que o processo de aprender a ensinar se prolonga durante toda a carreira docente.

Das práticas reflexivas, Zeichner (1993) enfatiza três aspectos: a atenção do professor direcionada tanto para dentro, para sua própria prática, como para fora, para as condições sociais nas quais se situa essa prática; a tendência democrática e emancipacionista e a importância dada às decisões do professor quanto a questões que levam a situações de injustiças dentro da sala de aula; a prática reflexiva como compromisso com a reflexão como prática social.

Entretanto, Zeichner (1993, p. 22-23) chama a atenção quanto à ilusão da reflexão quando se refere ao modo como se tem usado a noção de professor prático reflexivo. Ele atribui como contribuintes para o fracasso da emancipação quatro características. A primeira diz respeito ao desprendimento de esforços no sentido de ajudar os professores a imitar práticas sugeridas de investigações de terceiros e alheias às teorias e saberes advindos, tanto em suas práticas, como nas de outros professores. Caracteriza-se, aí, a insistência da racionalidade técnica sob 
a bandeira da reflexão. A segunda refere-se à exclusão docente do processo de pensar estratégias, planejar e de traçar objetivos para a docência. De modo geral, as academias e órgãos governamentais ligados à educação centralizam tais ações e, nesse caso, os professores nada fazem além de se ajustarem a determinações de outrem. A terceira característica é a tendência de se focalizar a reflexão dos professores em sua própria prática ou em seus alunos, negligenciando questões referentes às condições sociais que influenciam no trabalho docente e na reflexão individual. Isso faz com que alguns professores restrinjam sua ação à sala de aula, e os torna responsáveis por vários problemas existentes na educação, uma vez que não possuem a consciência de que essas questões problemáticas estão inseridas nas desigualdades sociais, econômicas e políticas (PAULA, 2011).

Entendendo a docência como ação que deve ser consciente, politizada e voltada para questões sociais mais amplas, adotamos as concepções de Kenneth Zeichner como principal referencial teórico para o desenvolvimento de nossa pesquisa.

\section{METODOLOGIA E CONSIDERAÇÕES GERAIS SOBRE OS ASPECTOS TEÓRICOS ADOTADOS}

Para apreensão e registros mais elaborados dos acontecimentos relativos à investigação de ações reflexivas na prática docente, observáveis em sala de aula, lançamos mão de uma abordagem etnográfica, uma vez que acreditamos que tal abordagem nos permite uma análise mais aprofundada das ações, já que se caracteriza por centrar as atenções no processo dos acontecimentos André (2003), o que está relacionado com nosso objetivo de pesquisa.

O campo para realização da pesquisa foi constituído por duas salas de aulas de $1^{\mathrm{a}}$ série do Ensino Médio de escolas públicas da rede estadual de Pernambuco. A escolha se deu a partir do perfil dos professores, traçado por meio de uma entrevista na qual foram identificadas as seguintes características: disposição em ter sua prática docente investigada; ser professor experiente e de escola pública; haver participado de cursos de formação continuada; apresentar disponibilidade para entrevistas, e permitir o registro videográfico de suas aulas. Entendendo que o foco deste estudo centrou-se nas ações reflexivas, inerentes à tendência do professor reflexivo, a definição do critério da experiência profissional ofereceu um campo propício à emergência de tais ações.

A fim da preservação de identidade dos professores pesquisados, foram adotados nomes fictícios para sua representação, a saber, Ricardo e Lucas.

Recorremos às categorias que se seguem a fim de que atingíssemos nossos objetivos. As categorias foram definidas a partir das concepções de Zeichner (1993), segundo o qual nos apoiamos para analisar a prática reflexiva. Os focos de análise foram construídos pelos autores deste artigo, partindo das categorias do autor supracitado. São elas: 
Quadro 1: Categorias teóricas e focos de análises.

\begin{tabular}{|c|c|c|c|}
\hline Categorias & Focos de análise & E & A \\
\hline $\begin{array}{l}\text { a) Participação ativa nos } \\
\text { processos de formação de } \\
\text { docentes. }\end{array}$ & $\begin{array}{l}\text { Se o professor busca a formação continuada; } \\
\text { vê carências em sua prática; é coconstrutor de } \\
\text { programas para sua formação. }\end{array}$ & & \\
\hline $\begin{array}{l}\text { b) Apreensão de que } \\
\text { ensinar se prolonga por } \\
\text { toda carreira docente. }\end{array}$ & $\begin{array}{l}\text { Se o professor reflete o interesse pela execução } \\
\text { do ensino, se considera e pratica a concomitância } \\
\text { pesquisar-ensinar. }\end{array}$ & & \\
\hline $\begin{array}{l}\text { c) Produção de } \\
\text { conhecimentos relativos ao } \\
\text { ensino de qualidade. }\end{array}$ & $\begin{array}{l}\text { Se o professor produz conhecimentos junto a seus } \\
\text { alunos, e se socializa os resultados em eventos } \\
\text { como fóruns e congressos. }\end{array}$ & & \\
\hline $\begin{array}{l}\text { d) Consideração à } \\
\text { experiência e produções } \\
\text { dos bons professores. }\end{array}$ & $\begin{array}{l}\text { Se o professor utiliza experiências bem sucedidas } \\
\text { de seus colegas docentes. }\end{array}$ & & \\
\hline $\begin{array}{l}\text { e) Compreensão do ensino } \\
\text { e de sua melhoria a partir } \\
\text { da reflexão sobre sua } \\
\text { experiência. }\end{array}$ & $\begin{array}{l}\text { Se o professor reflete sobre as implicações de } \\
\text { seu ensino na vida discente, na prática de seus } \\
\text { colegas, na inserção da escola na comunidade. }\end{array}$ & & \\
\hline $\begin{array}{l}\text { f) Atuação numa } \\
\text { perspectiva democrática e } \\
\text { emancipacionista. }\end{array}$ & $\begin{array}{l}\text { Se o professor concebe contrato didático, fomenta } \\
\text { a crítica discente e apoia deliberações coletivas. }\end{array}$ & & \\
\hline $\begin{array}{l}\text { g) Compromisso com a } \\
\text { reflexão como prática } \\
\text { social. }\end{array}$ & $\begin{array}{l}\text { Se o professor extrapola o raio de ação disciplinar } \\
\text { e considera a sala de aula como espaço de } \\
\text { trocas interativas. }\end{array}$ & & \\
\hline $\begin{array}{l}\text { Categoria } \\
\text { evidenciada. } \\
\text { Convencionamos } \\
\text { (célula rasurada) }\end{array}$ & \multicolumn{3}{|l|}{$\begin{array}{l}\text { Convencionamos } \mathbf{E} \text { para designar as entrevistas e } \mathbf{A} \text { para } \\
\text { as aulas }\end{array}$} \\
\hline
\end{tabular}

Algumas das categorias teóricas elencadas para a pesquisa não são, necessariamente, perceptíveis em situações de aula. Daí, recorremos a videografias e entrevistas. Salientamos que a simbologia (...) nas transcrições das falas faz referência à omissão de trechos.

\section{FUNDAMENTANDO OS INSTRUMENTAIS DE PESQUISA}

Para alcançarmos nosso objetivo específico de analisar depoimentos de ambos os professores acerca de concepções reflexivas na prática de ensino, usamos entrevistas semiestruturadas, versando perguntas que buscavam resgatar informações que remetessem às categorias, uma vez que na sala de aula tais categorias, supostamente, não são evidenciadas.

Pádua (2004) observa que numa entrevista semiestruturada o pesquisador elabora um conjunto de questões básicas sobre o tema em estudo, mas permite, e 
conforme a necessidade até instiga, que o entrevistado verbalize livremente sobre o determinado tema.

Para o objetivo específico, analisar a prática de ensino dos professores por meio de suas ações prático-reflexivas, recorremos à observação não participante registrada em vídeo.

Chizzotti (2006, p. 84) observa que "Na pesquisa qualitativa todos os fenômenos são igualmente importantes e preciosos: a constância das manifestações e sua ocasionalidade, a frequência e a interrupção, a fala e o silêncio". Neste estudo, justificamos nossa opção por técnicas que busquem contemplar o máximo de possibilidades na construção dos dados.

Posteriormente à sondagem pelo interesse em participar da pesquisa, frequentamos as salas de aulas dos referidos professores, portando a câmera filmadora, por período compreendido como suficiente para que os docentes atenuassem possíveis inibições. Dos vídeos, fizemos recortes, construindo blocos lógicos de trajetórias de aulas a fim de possibilitar que fossem feitas as devidas análises.

\section{CRITÉRIOS PARA ANÁLISE DOS DADOS}

A análise dos dados, que será descrita a seguir, achou suporte nas categorias teóricas do professor reflexivo segundo a perspectiva de Zeichner (1993). Todavia, estivemos atentos quanto ao possível surgimento de categorias dos teóricos Dewey e Schön, que seguem uma perspectiva empírica.

Para tanto, todo o material reunido com as filmagens passou por uma edição que foi ancorada nos referenciais teóricos da pesquisa, e os dados foram examinados tendo como referência a análise de conteúdo segundo a perspectiva de Bardin (1997).

As aulas videografadas foram caracteristicamente expositivas, e quando confrontadas com padrões interacionais concebidos por Marcuschi (2005), se caracterizaram ortodoxas por apresentarem interferências com participação de falas por parte dos estudantes, que variavam de um nível discreto a intenso, constituídas por trocas de turnos. As intervenções eram, geralmente, breves e voltadas para um tema de estudo pré-determinado pelo professor; o aceite de tais intervenções ocorria ou não, conforme a pertinência do professor.

São a "atuação numa perspectiva democrática e emancipatória" e o "compromisso com a reflexão como prática social" categorias teóricas de nosso estudo. Foram consideradas as possibilidades de que tais categorias se manifestassem nos turnos de nossos sujeitos de pesquisa, conforme variação e intensidade de suas trocas e seus aspectos qualitativos. Dessa maneira foi fundamentado nosso interesse pela convenção de Marcuschi (2005) quanto à aula ortodoxa, que segundo o autor é caracterizada por apresentar interferências com participação de falas por parte dos estudantes, que variam de nível discreto a intenso, constituídas por trocas de turnos, e as intervenções são, geralmente, breves e voltadas para um tema de estudo pré-determinado pelo professor. 
Os conteúdos discursivos das entrevistas foram analisados segundo Bardin (1997), e os protocolos de sala de aula a partir dos padrões interacionais descritos por Marcuschi (2005).

\section{ANÁLISES DOS DADOS}

Serão apresentados alguns estratos analíticos das entrevistas feitas com os professores pesquisados, as quais foram analisadas paralelamente às respostas a cada pergunta. Posteriormente, apresentaremos análises das ações dos professores em aula a fim de demonstrar o estado de evidência das categorias teóricas.

\section{SÍNTESE DAS ANÁLISES DAS AC̣ÕES DO PROFESSOR RICARDO}

Pensamos que, em certa medida, o professor reconhece a profissão como instrumento de trocas interativas e associa o ensino-aprendizado à cultura familiar, como algo histórico para si. Além disso, acreditamos que ele faça a opção pelo prolongamento do ensino-aprendizado em sua carreira docente, o que caracteriza uma categoria da prática reflexiva segundo Zeichner (1993). (Eu sempre defendi que a gente... construísse espaço para socializar toda a nossa construção... minha mãe foi a minha primeira professora ... no primeiro ano da universidade eu já comecei a ensinar... tá contribuindo com a sociedade... espero continuar ... por muito tempo...)

Verificamos, nesta pesquisa, a efetiva presença de aspectos da prática reflexiva, ao identificar, no professor Ricardo, uma pré-disposição em participar de todos os cursos de formação continuada a ele disponíveis; (... Eu sempre participei de capacitações ... me autocapacitar ... realizei oficina ... sucata...). Ele ainda reconhece a importância de trabalhar questões sociais, (... a gente derruba as matas... nossos... "descobridores"... vieram pra cá pra explorar e essa cultura... se realizou na gente, ... a gente precisa construir uma nova cultura...)

Ao revelar conteúdos intrínsecos aos processos progressistas de ensino-aprendizado, o professor Ricardo nos permite compreendê-lo como profissional que, no mínimo em discurso, relaciona-se às teorias de práticas docentes reflexivas (... tive uma formação política... sempre procurei ... o trabalho no meio popular... a gente ... fotografou ... o rio Capibaribe... discutiu,... apresentou esse material ...). O professor defende a socialização de experiências com colegas de trabalho e diz-se atento às implicações de seu ensino na vida dos estudantes (... a gente tem.... o protagonismo juvenil. É estimular a autonomia do jovem... o pensamento dele como agente de transformação...) e a outros aspectos, característicos da prática reflexiva, que estiverem presentes em seu cotidiano docente, conforme afirmou.

No que diz respeito à racionalidade técnica, pudemos registrar o status de superioridade, dispensado pelo professor, dos conhecimentos científicos em detrimento dos conhecimentos do cotidiano; além disso, em certa medida, 7 ele 
deposita nas mãos da academia a incumbência da construção de soluções para os problemas emanados das práticas docentes em escolas de ensino básico. (... A gente vai pra um curso... quando você volta pra escola.... termina a gente não implementando as vivência ... A gente está distante ano luz da academia... A gente precisa ter uma política onde... pudesse tá se encontrando.)

O professor consegue identificar, empiricamente, um dos problemas cruciais da racionalidade técnica, a ineficácia dos programas desconectados do cotidiano escolar. Ele defende a formação continuada entre colegas em seus espaços escolares, demonstrando dar certa independência e autonomia para a formação continuada. Zeichner (1993, p. 26) ressalta a importância de "construir comunidades de aprendizagem, nas quais os professores apoiam e sustentam o crescimento uns dos outros.".

O professor identifica, além das limitações de programas baseados na racionalidade técnica, o fato de alguns professores acadêmicos - geralmente ligados aos modelos tradicionais de ensino - subestimarem a capacidade de reflexão dos que procuram as academias ou a elas são dirigidos pelo governo ou por outros programas de capacitação.

Quanto às aulas, registramos do professor o uso de analogias do tipo "com as letras... a gente constrói as palavras; com os símbolos dos elementos nós escrevemos o quê? as fórmulas das substâncias." e a preocupação em relacionar conteúdos programáticos com questões do cotidiano dos estudantes, embora não estivesse, necessariamente, contextualizando os conteúdos. Registramos, ainda, que as aulas basearam-se em retórica conteudística clássica ou, segundo protótipo de aulas concebido por Marcuschi (2005), as aulas do professor Ricardo foram caracteristicamente ortodoxas, com participação de falas discretas por parte dos estudantes, conforme pode ser observado nos recortes de transcrições de fragmentos de aulas. Segundo Marcushi (2005), tais recortes podem ser considerados trajetórias discursivas, como veremos a seguir:

Trajetórias discursivas 2 e 5: Tabela Periódica

\begin{tabular}{|c|c|c|}
\hline 02 & pfo: & /.../ ouro... são classificados de metais? Por que... conduzem /.../ \\
\hline 04 & est: & Professor! \\
\hline 05 & pfo: & Pois não? / .../ carbono, \\
\hline 06 & est: & Professor! \\
\hline $\begin{array}{l}09 \\
10\end{array}$ & pfo: & $\begin{array}{l}\text { /.../ o não metal, em geral, não conduz /.../Por favor! A partir dessas letras } \\
\text { aqui, três, quatro letras dessas, forme uma palavra aqui! }\end{array}$ \\
\hline 14 & est: & Ha-ha-ha. Uva? ((a estudante sorri aparentemente acanhada)) \\
\hline
\end{tabular}

\begin{tabular}{|l|l|l|}
\hline 01 & pfo: & /.../ elétrons do oxigênio $1 \mathrm{s2,} \mathrm{2s2,} \mathrm{2p4.} \mathrm{Quando} \mathrm{eu} \mathrm{somar} \mathrm{aqui,} \mathrm{dá} \mathrm{quanto?}$ \\
\hline 02 & est: & Oito! \\
\hline 05 & est: & Seis! \\
\hline 12 & pfo: & /.../ a IUPAC, uma organização que estabelece regra para química ... \\
\hline 17 & pfo: & /.../ Pra que serve o leite de magnésia? Pode corrigir a acidez /.../ \\
\hline
\end{tabular}


A situação acima, uma exceção às intervenções discretas por parte dos estudantes, se deu a partir de uma aparente dificuldade advinda da estratégia utilizada pelo professor. Ao perceber a turma estática ele resolve mudar o rumo da aula recorrendo à participação de estudantes no quadro, o que, de acordo com Schön (2000), pode ser caracterizado como momento de reflexão-na-ação.

Entretanto, a participação das estudantes no quadro não passou de uma ação isolada, não voltando a acontecer nas aulas. A isso, podemos somar a desconsideração do professor em relação às concepções prévias dos estudantes para ter caracterizado o cenário construído em aula.

Finalmente, verificamos que apesar de um discurso formado por elementos característicos de práticas reflexivas, as ações do professor foram, predominantemente, permeadas por elementos da racionalidade técnica, deflagrando acentuada incoerência entre o que foi enunciado e o que foi praticado. Isso nos remete a Schön (apud NÓVOA, 1992) que ressalta que "A confrontação com os dados diretamente observáveis produz muitas vezes um choque educacional, à medida que os professores vão descobrindo que atuam segundo teorias de ação diferentes daquelas que professam". Isso ficou caracterizado, uma vez que o professor não remeteu sua prática às categorias teóricas crítico-reflexivas do tipo: conceber o ensino como prática social; atentar para dentro e para fora de sua própria prática; atentar para as condições sociais nas quais se situa sua prática; atuar numa perspectiva democrática e emancipacionista; comprometer-se com a reflexão como prática social.

Percebemos que o professor Ricardo não conseguiu repetir a performance da entrevista. Embora houvesse contemplado todas as categorias em situação de entrevista, em situação de aula nenhuma delas esteve presente.

\section{SÍNTESE DAS ANÁLISES DAS AC̣̃̃ES DO PROFESSOR LUCAS}

Retomando nossa proposta, identificar ações reflexivas dos professores tomando como base em entrevista registrada em áudio, e aspectos da prática docente a partir de trajetórias discursivas registradas em vídeo, faremos a contraposição dos resultados.

Registramos que o professor Lucas reconhece a importância de trabalhar questões sociais, concebe como paliativas as ações governamentais relativas à resolução dos problemas da educação no Estado (Falar de presente fica dificill... de futuro, muito mais... o Governo de Estado tem trabalhado a escola como uma indústria... sem perceber que tá tratando com recursos bumano...) e defende a socialização de experiências docentes junto aos colegas professores. (... a gente... tem trocado ideias... sempre que eu tenho algo... que dá pra acoplar com os meus ideais... eu percebo que eu tenho crescido...). Para Zeichner (1993), o professor reflexivo reconhece a riqueza da experiência das práticas dos bons professores.

Em sua fala, mostra-se atento às implicações de seu ensino na vida dos estudantes e reconhece a necessidade de trabalhar pela emancipação dos discentes, 
entretanto, salienta que tal questão se constitui num grande desafio, uma vez que os estudantes foram levados, culturalmente, a estados de acomodação (... pra a gente é difícil, pro aluno é mais ainda... eles veem a gente como algo pra transmitir... a função da gente não é essa ... a gente tá preparando pra vida ....)

Quanto aos objetivos de ensino, aspecto relevante numa prática reflexiva, esse professor reconhece a necessidade de extrapolação do ambiente de sala de aula. Tal preocupação foi registrada tanto em sua fala, durante a entrevista, quanto em sua prática em sala de aula, o que nos fez perceber, em alguns momentos, ligações entre seu ensino e questões mais amplas da sociedade. (...Cada um desses alunos tem seus objetivos...)

Em relação aos cursos de formação continuada, o professor Lucas verifica, objetivamente, que os saberes apreendidos não são contemplados com eficácia, uma vez que identifica algumas dificuldades no que diz respeito à articulação desses saberes com a realidade vivenciada no contexto escolar (... a gente tem buscado recursos, no caso a especialização ... só que na nossa realidade é totalmente diferent ....)

Ainda com referência à formação, registramos, em sua fala, que além de não haver produzido, efetivamente, conhecimentos para a educação como um todo (... não tenho conseguido tempo... fazer algo novo... vou pra internet fazer alguma pesquisa... não consigo... aplicar.) também não tem buscado formação continuada. (Tenho participado... quando me é criado oportunidade... buscar lá fora... eu não tenho feito...).

Verificamos que o professor Lucas desenvolveu suas aulas de forma ortodoxa, tendo como base um sequencial de conteúdos advindos de livros didáticos. Quanto a sua ação em sala de aula, mostrou-se provocante e atento às interações, embora aparentemente não haja conseguido o êxito requerido, conforme pode ser observado em recortes de transcrições de trajetórias discursivas de aulas, apresentados a seguir:

Trajetória discursiva1: Distribuição eletrônica

\begin{tabular}{|c|c|c|}
\hline 01 & pfo: & /.../ A gente vai ver distribuição eletrônica. Eu acho que vocês se lembram... \\
\hline 03 & est: & Muito pouco! \\
\hline $\begin{array}{l}04 \\
05 \\
06\end{array}$ & pfo: & $\begin{array}{l}\text { Muito pouco, né? Então a gente vai tentar melhorar isso aí e tentar avançar } \\
\text { um pouquinho mais /.../ Então, o que é a distribuição eletrônica? } \\
\text { /.../ modelo que é o de Bohr-Rutherford /.../ } 45 \text { menos } 18,23 \text {, não é? Não é } 23 ?\end{array}$ \\
\hline 11 & est: & Nem ele sabe! \\
\hline 12 & pfo: & ... 18, vai sobrar quanto? 9! Mas 9 vai pra última camada, posso deixar? Posso? \\
\hline 16 & est: & Não, vai ser 8. \\
\hline 17 & pfo: & /.../ Dessa distribuição eletrônica tem. Tá claro? \\
\hline 21 & est: & Não, eu não tô entendendo o que o senhor tá dizendo! \\
\hline 22 & pfo: & ... não? ... Eu vou tentar mostrar de uma maneira mais ilustrativa /.../ \\
\hline
\end{tabular}


Sendo assim, pensamos poder inferir que o referido professor remeteu sua prática, timidamente, às categorias teóricas crítico-reflexivas, como: conceber o ensino como uma prática social, favorecer as interações em sala de aula; atuar numa perspectiva democrática e emancipacionista; manter abertura para que os estudantes expressem seus pontos de vista; conceber o processo de compreensão e melhoria de seu ensino começando da reflexão sobre sua experiência. O professor buscou, num breve instante de uma das aulas, refletir sobre as implicações de seu ensino na vida de seus estudantes.

Trajetória discursiva 4: Distribuição eletrônica

\begin{tabular}{|c|c|l|}
\hline 02 & pfo: & É...é. Minha conta tá errada! \\
\hline 03 & est: & Dá 8, professor! \\
\hline 07 & pfo: & $\begin{array}{l}\text {... tem que questionar. Deus fez... e você errou, eu também tenho direito ... } \\
\text {... Você precisa e não fez nada! Num fique olhando não! ... }\end{array}$ \\
\hline 10 & est: & É porque eu não sei fazer, não! \\
\hline 11 & pfo: & Sabe sim! Você já me mostrou que sabe. Olhem! Tô preocupado! \\
\hline 14 & pfo: & $\ldots$ responda! Você quer dizer que todo mundo sabe mais do que você? \\
\hline
\end{tabular}

Embora o professor Lucas não haja contemplado todas as categorias em entrevista, durante a aula ele desenvolveu ações que remeteram às categorias: atuação numa perspectiva democrática e emancipacionista e compromisso com a reflexão como prática social, o que pode ser observado, anteriormente, em situações práticas.

\section{VISÃO GERAL DAS SÍNTESES DAS ATUAC̣ÕES DOS PROFESSORES RICARDO E LUCAS}

No que diz respeito às inferências realizadas sobre as práticas do professor Ricardo, observamos que nas ações em sala de aula os aspectos relativos à prática reflexiva - referencial das categorias teóricas do estudo - não foram evidenciados. Quanto ao professor Lucas, tais aspectos, embora timidamente, fizeram-se presentes. Entretanto, em suas entrevistas, ambos os professores trouxeram à tona aspectos das teorias que fundamentam as práticas reflexivas, sendo o professor Ricardo mais enfático, conforme observamos no quadro a seguir: 
Quadro2: Categorias teóricas evidenciadas pelos professores Ricardo e Lucas

\begin{tabular}{|l|l|l|l|l|}
\hline \multicolumn{1}{|l|}{ Categorias evidenciadas } & \multicolumn{2}{l|}{ Ricardo } & \multicolumn{2}{l|}{ Lucas } \\
\hline Categorias & E & A & E & A \\
\hline a) Participação ativa nos processos de formação de docentes. & & & & \\
\hline $\begin{array}{l}\text { b) Apreensão de que ensinar se prolonga durante toda a } \\
\text { carreira docente. }\end{array}$ & & & \\
\hline c) Construção de conhecimentos relativos ao ensino de qualidade. & & & & \\
\hline $\begin{array}{l}\text { d) Consideração pela riqueza relativa à experiência da prática } \\
\text { dos bons professores. }\end{array}$ & & & & \\
\hline $\begin{array}{l}\text { e) Compreensão do ensino e de sua melhoria, começando pela } \\
\text { reflexão sobre sua experiência. }\end{array}$ & & & & \\
\hline f) Atuação numa perspectiva democrática e emancipacionista. & & & & \\
\hline g) Compromisso com a reflexão como prática social. & & & & \\
\hline
\end{tabular}

Como podemos perceber na tomada geral do quadro acima, enquanto o professor Ricardo, em situação de entrevista, contempla as categorias teóricas integralmente, o mesmo não acontece em situação de aula, na qual tais categorias não foram evidenciadas.

Por outro lado, o professor Lucas, apesar de não contemplar em entrevista as categorias a e c, em situação de aula contempla duas outras importantes categorias, no caso, $\mathbf{f}$ e $\mathbf{g}$.

A opção por entrevistas e videografia nos permitiu verificar, no momento do cruzamento dos dados, as dificuldades dos professores em aliar seus discursos a suas práticas, o que, segundo Schön (2000), possivelmente nutre relação com a formação que eles receberam. Schön (apud NÓVOA, 1992, p. 90) observa que "Não é suficiente perguntar aos professores o que fazem, porque entre as ações e as palavras há por vezes grandes divergências".

Outra questão que consideramos pertinente ao debate, e que certamente traz instigações adicionais, diz respeito aos conteúdos abordados pelos professores.

O professor Ricardo, apesar de haver trabalhado um conteúdo - tabela periódica - de aparente facilidade para contextualização e interações dialógicas, pautou suas aulas na "transmissão de conhecimentos", desenvolvendo interações dialógicas mínimas, por meio do uso de conteúdos dos livros didáticos, por vezes relacionados ao cotidiano discente.

Quanto às ações reflexivas do professor Ricardo, só foi possível detectá-las em situação singular, no momento em que ele solicita que os estudantes participem da aula indo ao quadro, caso supostamente caracterizado como reflexão-na-ação, relativa à perspectiva de Schön (2000).

Por sua vez, o professor Lucas, mesmo atuando com um conteúdo potencialmente abstrato - distribuição eletrônica em orbitais quânticos concebidos por 
Chassot (1995, p. 113) “como inimagináveis pelos alunos"- articulou uma estratégia alicerçada em analogias do tipo: “... os elétrons vão tá distribuidos ... distâncias diferentes como se fosse camadas, feito uma cebola” que, se não permitiu o desenvolvimento de abstrações por parte dos estudantes, viabilizou interações mais qualitativas.

Oportunamente, registramos que mesmo apresentando dificuldades para dar significação aos conteúdos, o professor Lucas buscou, sistematicamente, o diálogo e outros tipos de participação, como andar pela sala circulando entre as carteiras dos estudantes, o que, em nosso entender, desmistifica concepções que, por vezes, transformam determinados conteúdos em "caixas pretas", isto é, em algo misterioso, de difícil entendimento. Para agir como tal, o professor Lucas certamente recorreu a estados de reflexão-na-ação, perspectiva de Donald Schön (2000).

O professor Lucas também instigou os estudantes a questionar, o que, em certa medida, favorece a emancipação. E, ainda, apresentou categorias empíricas, deweyanas quanto à prática reflexiva, como o espírito aberto, a responsabilidade e a sinceridade.

\section{CONSIDERACְÕES FINAIS}

Neste estudo, usamos como categorias teóricas os aspectos centrais da teoria de Zeichner (1993) quanto à prática reflexiva. Dessa maneira, faremos algumas considerações finais de acordo com essa perspectiva. No decorrer dos trabalhos, surgiram as categorias empíricas: a) reflexão-na-ação: teoria prático-reflexiva de Donald Schön, para os professores Ricardo e Lucas; b) espírito aberto, responsabilidade e sinceridade: da teoria prático-reflexiva de John Dewey, para o professor Lucas; e c) responsabilidade e sinceridade: da teoria prático-reflexiva de John Dewey, para o professor Ricardo.

O estudo realizado com ambos os professores nos possibilitou identificar diversos aspectos relativos à prática reflexiva. Entretanto, em sala de aula, no momento de suas práticas, esses professores apresentaram-se timidamente quanto a ações reflexivas.

Tais fatos nos remetem às perguntas de pesquisa: estarão os professores de Quimica apresentando ações reflexivas no cotidiano de suas práticas docentes? Como tais professores se expressam discursivamente em relação à formação e atuações prático-reflexivas?

Os instrumentos utilizados para a construção dos dados, a análise pormenorizada das falas e os recortes das trajetórias discursivas de assuntos vivenciados por cada professor, em contraste com a fundamentação teórica oportunizada pelos autores Zeichner (1993), Schön (2000) e Dewey (apud Zeichner, 1993), permitiu-nos fazer algumas inferências que serão descritas a seguir.

As ações reflexivas na prática de cada professor pesquisado foram expressas timidamente e enfatizaram perspectivas teóricas diferentes. Ressaltamos que tais professores levaram para a sala de aula conteúdos programáticos afins, embora vivenciados em contextos sociais diferentes, segundo as características peculiares da escola e região. 
O fato de os professores terem trabalhado com conteúdos diferentes, e consequentemente com possibilidades de abstração também diferentes, constituiu-se situação de destaque em nossa pesquisa, uma vez que observamos que o professor que trabalhou o conteúdo supostamente mais abstrato estabeleceu interações, junto aos estudantes, notavelmente mais promissoras. Isso nos levou a inferir que o referido professor recorreu a ações reflexivas, e nos chamou a atenção que o fato de o conteúdo apresentar perfil de complexidade mais elevado não implica, necessariamente, em geração de dificuldades para interações promissoras em sala de aula.

Remetendo-nos ao tempo de formação, à participação de formação continuada e à experiência dos professores, queremos destacar a possibilidade de eles terem a oportunidade de optar por ações relativas a práticas reflexivas. Por isso, adotamos referenciais que remetessem a práticas reflexivas, como Zeichner, em particular, pela visão mais ampla da referida prática.

Das categorias teóricas investigadas: a) participação ativa nos processos de formação de docentes; b) apreensão de que ensinar se prolonga durante toda a carreira docente; c) construção de conhecimentos relativos ao ensino de qualidade; d) consideração pela riqueza relativa à experiência da prática dos bons professores; e) compreensão do ensino e de sua melhoria começando pela reflexão sobre sua experiência; f) atuação numa perspectiva democrática e emancipacionista; g) compromisso com a reflexão como prática social, podemos concluir que:

a. Em situação de entrevista, o professor Ricardo contemplou todas as categorias, enquanto o professor Lucas deixou de contemplar as categorias a e c.

b. Em situação de aul,a o professor Ricardo não contemplou nenhuma das categorias, enquanto o professor Lucas contemplou as categorias $\mathbf{f}$ e $\mathbf{g}$.

Pressupomos, com base em nossos aportes teóricos, que o presente contexto pode estar relacionado aos tipos de formação gestados pelas academias, que podem ser baseados na racionalidade técnica. Por isso, supomos que investimentos em formação baseada na perspectiva da prática reflexiva, em que a pesquisa é inerente ao processo, em que a formação leva em consideração a experiência de quem ensina, e ainda em que os professores em formação participam ativamente de todo processo de construção e implementação da proposta, poderão contribuir para uma prática reflexiva que subsidie a prática docente dos professores no seu contexto escolar.

\section{REFERÊNCIAS}

ANDRÉ, M. E. D. A. Etnografia da prática escolar. 9. ed. Campinas (SP): Papiros, 2003.

ALMEIDA, M. A. V.; BASTOS, H. F. B. N. O professor de química e o processo reflexivo sobre sua ação em sala de aula. In: ENCONTRO NACIONAL DE PESQUISA EM EDUCAÇÃO EM CIÊNCIAS, 4.,2003. Bauru, SP. Anais... Bauru: ABRAPEC, 2003.

BARDIN, L. Análise de conteúdo. Lisboa, Edições 70, 1997.

ALTARUGIO, M. H.; VILLANI, A. O papel do formador no processo reflexivo de professores de ciências. Investigações em Ensino de Ciências, Porto Alegre, V15(2), pp. 385-401, 2010. 
CHASSOT, A I. Para que (em) é útil o ensino? Alternativa para um ensino (de Química) mais crítico. Canoas: Ed. da ULBRA, 1995.

CHIZZOTTT, A. Pesquisa em ciências humanas e sociais. 8 ed. São Paulo: Cortez, 2006.

MALDANER, O. A. A formação continuada de professores de química. Ijuí: Ed. UNIJUí, 2000.

MARCUSCHI, L. A. O diálogo no contexto da aula expositiva:continuidade, ruptura e integração. In: Dino Preti. (Org.). Diálogos na fala e na escrita: Projetos Paralelos. Vol. 7. São Paulo: Associação Editorial Humanitas, 2005.

MORTIMER, E. F.;SILVA, P. S. Formação continuada e mudanças nas práticas pedagógicas:o que dizem aos professores de química. In: ENCONTRO NACIONAL DE PESQUISA EM EDUCAÇÃO EM CIÊNCIAS, 4.,2003. Bauru, SP. Anais... Bauru: ABRAPEC, 2003.

NERY, B. K. ; MALDANER, O. A. Ações Interativo-Reflexivas na Formação Continuada de Professores. Quimica Nova na Escola, São Paulo, Vol. 31, n 2, 2009.

PÁDUA, E. M. M. Metodologia da pesquisa: Abordagem teórico-prática.10ª ed. Campinas, SP: Papirus, 2004.

PAULA, C. S. M. M. O professor como agente da construção da teoria e da prática. Revelli - Revista de Educação, Linguagem e Literatura da UEG. Inhumas, GO, v. 3, n. 1, p. 18-3, 2011.

PEREIRA, J. E. D. Formação de professores: pesquisas, representações e poder - Belo Horizonte: Autêntica, 2000.

RODRIGUES, D. B; SOBRINHO, J. A. C. M (orgs). Formacãa de professores e práticas docentes - olhares contemporâneos. Belo Horizonte, MG: Ed. Autêntica, 2007.

ROSA-SILVA, P. O. ; JÚNIOR, Á. L. ; LABURÚ, C. E. Análise das reflexões da professora de ciências sobre a sua relação com os alunos e implicações para a prática educativa. Revista Ensaio Pesquisa em Educação em Ciências. Belo Horizonte, v.12, n.01, pp.63-82, 2010.

SANTOS, B. F. e SANTOS, L. N. Formação continuada de professores de química:qual modelo, qual formação?. ENCONTRO NACIONAL DE PESQUISA EM EDUCAÇÃO EM CIÊNCIAS, 4.,2003. Bauru, SP. Anais... Bauru: ABRAPEC, 2003.

SCHÖN, D. Formar professores como profissionais reflexivos. IN: NÓVOA, Antônio (org.) Os professores e sua formação. Lisboa: Dom Quixote, 1992.

SCHÖN, D. Educando o profissional reflexivo: um novo design para o ensino e a aprendizagem. Porto Alegre: ARTMED, 2000.

SILVA E. L., SALES M. G. P. e CHINEN, J. Investigando a prática docente dos professores de química d.e. - Mauá, discutindo-a e confrontando-a com os pressupostos presentes nos PCNS. In: ENCONTRO NACIONAL DE PESQUISA EM EDUCAÇÃO EM CIÊNCIAS, 4.,2003. Bauru, SP. Anais... Bauru: ABRAPEC, 2003.

ZANON, L. B.; SCHNETZLER, R. P. Interações triádicas entre licenciandos, professores e formadores na licenciatura de química/ciências. ENCONTRO NACIONAL DE PESQUISA EM EDUCAÇÃO EM CIÊNCIAS, 4.,2003. Bauru, SP. Anais... Bauru: ABRAPEC, 2003.

ZEICHNER, K. M. A formaşão reflexiva de professores por ideias e práticas. Lisboa: Educa, 1993.

Data do Recebimento: 11/01/2012

Data de Aprovação: 09/06/2012

Data da Versão Final: 05/08/2012 